\title{
Scientific Principles Versus Practical Realities: Insights From Organizational Theory to Individual Psychological Assessment
}

\section{UTE-CHRISTINE KLEHE \\ University of Amsterdam}

Individual psychological assessment (IPA) for executive and top management positions isn't an easy job. Still, knowledge gained over decades of scientific study suggests that we rely on structured job and organizational analyses; the construction of appropriate high- and low-fidelity simulations, cognitive tests, and affective inventories suitable in content and difficulty (Ones \& Dilchert, 2009; Rubenzer, Faschingbauer, \& Ones, 2000); as well as a structured and mechanical combination of the resulting information (Egisdóttir et al., 2006; Grove, Zald, Lebow, Snitz, \& Nelson, 2000). And we will likely still remain painfully aware of the poor ability of even our most refined assessments for predicting executives ${ }^{\prime}$ performance.

Silzer and Jeanneret (2011) "disagree with those who have a simplistic view of executive roles" and argue that they "do not think a job-sampling approach to establish job relatedness [...] is feasible, given the complexity of executive jobs and the significant influence of contextual factors" and

Correspondence concerning this article should be addressed to Ute-Christine Klehe.

E-mail: u.klehe@uva.n!

Address: Arbeids- \& Organisatiepsychologie, Universiteit van Amsterdam, Roetersstraat 15, 1018 WB Amsterdam, The Netherlands

Many (though not all) of the ideas voiced in this commentary are based on Klehe (2004), which in lum is largely based on Oliver (1991) and has found first empirical support by König, Klehe, Berchtold, and Kleinmann (2010). that "test batteries would only evaluate individuals on very general factors (mostly cognitive factors) that are far too broad to differentiate specific executive success." Rather, they stress the expertise of the assessing psychologist and "the clinician's 'genuine creative act' of generating a 'structuraldynamic hypothesis'," arguing for assessors' proposed ability to sort and integrate observations in multiple ways, to identify "broken legs" and to adapt the focus of the testing to the information so far received.

Many reasons may explain why even scientist-practitioners discard the advice of their own discipline, ranging from implicit beliefs (Highhouse, 2008), classic attribution errors, and decision-making biases (Phillips \& Gully, 2008) to the evolutionary novelty of our statistical decision rules for a task (predicting others' behavior) as old as man himself (Colarelli \& Thompson, 2008). Klimoski and Jones (2008) argued to also consider the context of personnel selection. Already conceptualized (Klehe, 2004) and proven useful (König et al., 2010) for personnel selection in general, this commentary tries to apply this idea to IPA in particular.

\section{Caught Between Multiple Stakeholders}

Following their financial and social objectives, psychological assessors face many competing stakeholders. Compliance with 
the demands of scientific and professional communities, client organizations, and candidates tested raises prestige, stability, legitimacy, professional acceptance, social support, access to resources, attraction of personnel, and invulnerability to questioning. Yet, given their multitude and conflicting nature, no decision maker can satisfy all demands at once-and will thus adopt, compromise, avoid, defy, or even manipulate demands in striving toward overall stability and legitimacy (Oliver, 1991).

\section{The Community}

The scientific and professional community, addressed in $1 O P$, offers stability and legitimacy by creating incremental knowledge and refining the boundaries up to which this knowledge will hold true (see Silzer and Jeanneret's call for "assessment databases ... available to researchers ... to study ... key research issues and policy issues"). Science also creates legitimacy by impacting best-practice recommendations and norms (e.g., ISO) and by setting standards for accreditations and licensing. In return, the community requires adherence to certain rules, for example, acknowledging empirical findings and resulting advice of earlier work (e.g., on the value of critical incidents, general mental ability [GMA], and mechanical integration) and providing empirical proof that any delineation from such advice is of incremental value.

\section{Clients}

Our community may have opinions, but it does not pay the bills. Rather, client organizations, themselves often amateurs in IPA (Smith \& Howard, 2009), hire psychologists in the hope that the resulting IPA "is based on sound psychological principles, theory, and research" (Silzer \& leanneret), that is, backed by the above scientific community. Yet in the end, clients' willingness (financial resources allowing) to invest into long-term cooperations with assessors also for later vacancies is primarily a question not of scientific backing but of whether the assessment appears "insightful and accurate" and if it adds "significant value to the selection process," thus promising to be "a sound and useful investment" (Silzer \& Jeanneret). This may be particularly true when a selection is part of a comprehensive succession management process (Day, 2009) and when organizational decision makers gain the impression that the assessor understands and contributes to this longterm perspective.

Yet, client organizations, too, are subject to multiple conflicting demands. Thus, an organization may not strive for the objectively best candidate, but for an easy, fast, and suitable solution for a pressing problem (Klimoski \& Jones, 2008). Long-term economic benefits are thus often discounted in the face of certain short-term costs, and organizations tarry to invest the money and manpower needed for preparing a solid IPA with no guarantees given about the resulting recommendation's tenor or eventual success (Klehe, 2004; König et al., 2010).

In addition, executive decision making happens in a highly politicized environment. Within organizations, different stakeholders hold different interests, and a new executive will not only need to fit to the official requirements of the position but will also be decided upon on the basis of the unofficial political and power struggles, coalitions, and competitions within the organization (Kraut, 2009; Oliver, 1991). In such politicized environment, a standardized, numeric, and directly comparable IPA of different candidates might appear more threatening than helpful. This also reflects Oliver's (1991) argument that organizations will try to resist institutional pressures perceived as constraining an organization's autonomy and Dipboye's (1994) argument that organizations often prefer unstructured selection procedures as the inherent ambiguity of unstructured procedures may prevent scrutiny and monitoring of the selection process by outside parties, such as the HR department or governmental agencies. 


\section{Candidates}

Silzer and Jeanneret argue that unstructured or semi structured interviews allow assessors to "probe and collect additional information relevant to a concern or a dimension" and to "pursue behavioral leads in an interview. They can adapt to new information and changing dynamics in the interview." Yet, candidates usually prefer unstructured interviews, too, because they can set these leads: They see a greater control and ability to influence the desired outcome with unstructured, compared to structured procedures (Latham \& Finnegan, 1993), conveying a consistent and well-crafted picture of themselves. The resulting report then easily suggests that the assessment psychologists really know this person-but reflects a negotiated outcome more than an independent assessment. Thus, particularly because executive candidates are both assessment savvy (Silzer \& Jeanneret) and are used to making complex and wide-reaching decisions based on insufficient information (Smalley, 2009), the use of structured procedures is so important, even though negotiated "round" stories may more easily find the approval of both candidates and of the clients requesting an insightful profile.

Particularly candidates aware of their high societal-and soon likely organizational-status may demand a sense of appreciation and welcome, and doomed is thus the assessor who smudges a positive impression of a client organization. Applicants infer an organization's values, beliefs, and assumptions from the selection process (e.g., French, 1987; Murphy \& Davidshofer, 1991; Rynes, Heneman, \& Schwab, 1980; Schneider, 1972) and prefer interviewers who are attentive, warm, thoughtful, socially perceptive, and likeable in the way they run the interview (Dipboye, 1992) - all of which is easier to accomplish during an unstructured or maybe a semistructured interview than during a more structured interview. Unstructured procedures also facilitate other aspects of perceived fairness, such as opportunity to perform, a two-way communication, and a higher degree of interaction, thus easing some of the unnaturalness, uneasiness, and stiffness of the selection process, and facilitating the process for both parties (Dipboye, 1994). For this reason, too, candidates usually prefer unstructured procedures over structured ones (Conway \& Peneno, 1999; Schuler, 1992), and unstructured interviews in particular can serve as recruitment tools just as much as selection tools.

\section{Context and Competition}

Research on the mimetic view of organizational conformity (DiMaggio \& Powell, 1983; Tolbert \& Zucker, 1983) shows that the diffusion of a practice or belief influences its perceived legitimacy and hence adoption. That is, when institutional rules or norms are broadly diffused, they reflect taken-for-granted understandings of what constitutes legitimate or rational behavior, and their social validity is hardly questioned. Organizations may even conform because it does not occur to them to do otherwise. This is less likely to happen when specific practices are not that common. Silzer and Jeanneret's "reservations about executive search consulting firms using individual assessments to advocate for and promote their candidates to client organizations" are thus fully warranted, yet this competition is not only eating a rather large chunk of the lucrative cake (e.g., Smith \& Howard, 2009) but is also setting the tone and implicit expectations about the predictability of performance.

As Silzer and Jeanneret imply, a core issue in the competition with headhunters lies in their different business model: Unlike psychological assessors interested in as objective and essentially neutral an IPA as possible, most headhunters only get paid once they manage to make organizational decision. makers fall in love with their chosen candidate and vice versa (Finlay \& Coverdill, 2002). The resulting grooming of and sales pitch for the proposed candidate then often implies a far greater belief in the validity of the recommendation made 
than any serious psychologist would be able to defend on scientific grounds. Faced with the dilemma between scientifically appropriate modesty on the one hand and the knowledge of the own professions' superiority for predicting performance on the other hand, not to speak of own business interests, psychologists can either try to discredit their competition (likely not a very fruitful endeavor, given the dissemination of headhunters in executive placement) or give in to the easily shared myths about the predictability of human behavior (Highhouse, 2008), thus further strengthening these myths.

Besides numerous psychological (Highhouse, 2008) and even evolutionary (Colarelli \& Thompson, 2008) reasons for using the latter approach, organizational theory suggests that it will also be fostered by the innate nature of the task at hand. After all, executive jobs are highly complex, and predicting executive performance is an uncertain, risky, if not close to impossible task (Silzer, 2005; Smalley, 2009). Particularly under conditions of uncertainty, however, when future states of the world cannot be anticipated and accurately predicted (Pfeffer \& Salancik, 1978), organizations (i.e., here assessment experts) exert great effort to reestablish real or at least perceived control and stability. They tend to overestimate the certainty of their decisions and become more likely to imitate other organizations in their field (DiMaggio \& Powell, 1983; Galaskiewicz \& Wasserman, 1989).

Finally, headhunters hold still another advantage over assessment psychologists by being an excellent tool in the politicized environment of executive decisions. After all, it is not the organization overall, but only their direct client (e.g., the hiring department), whom headhunters need to serve to make an income. In this, headhunters fulfill numerous buffering roles also between departments within the same organization (e.g., shielding an organization's hiring department from the HR department [Finlay \& Coverdill, 2002]), thus serving as a powerful tool in organizational politics. A professional and truly neutral psychological assessor will be unable (and one might argue unwilling) to fulfill such a role.

\section{Content}

Organizations react to some pressures with more resistance than to others. This happens, first, when a pressure constrains a decision maker's perceived autonomy (Oliver, 1991), and past research on personnel selection suggests that this effect hampers the dissemination of structured selection procedures. It happens, second, when the pressure's content conflicts with the organizations' own economic and social objectives.

Economically, psychological assessors want to win and keep a piece of the lucrative business of IPA while containing the costs involved (e.g., for using external testing material). This in turn raises the importance of satisfying clients, finding acceptance with candidates, and outperforming (or at least appearing to outperform) the competition. Endorsement by the professional community, in turn, will contribute only indirectly to the business at hand by further enhancing the assessment psychologist's professional credibility.

Socially, however, we might deal with nothing less than our professional identity. This identity influences how we react to different IPA procedures and what procedures we want to see endorsed (or not) by official norms and during professional education and licensure. Silzer and leanneret express a clinically rooted identity when they note that "We believe that we are in fact psychologists and that psychological judgment is critical to IPA" and that "some assessors have a natural interest and curiosity about people. They are better observers of human behavior and notice subtle actions and people differences. They naturally start assembling their own behavioral norms by observing others.... whereas other assessors seem more mechanistic and show weaker behavioral observations skills." Taking this perspective, structured 
interviews may feel monotonous and boring without allowing to build a rapport with the interviewee (Dipboye, 1994; Harris, 2000) - and it may even call to question as to whether one needs a psychology degree to run them. Yet, believing in the empirical science of psychology (and hating that lame "Psychologist? So you can read my mind!" pickup line), l'd counter "I believe that ... the use of empirical psychological findings is critical to IPA" - and would thus find it irresponsible to waste decades of practice and hundreds of second-rate advices into the development of an assessment expertise that may be modestly better than no expertise at all (Speng!er et al., 2009), but hardly better than the statistical results obtainable on Day 1 (Egisdóttir et al., 2006). Similarly, either side could now passionately argue about the validity of these claims - which brings us to the section on how to handle all these conflicting pressures.

\section{Reactions to Organizational Pressures}

Given the rather diverging calls by different stakeholders on how IPA should look, assessors face the strategic choice to acquit, compromise, avoid, defy, or even manipulate any of these pressures. Acquiescence includes conscious compliance (e.g., relying on a well-validated GMA-test rather than assessing "smarts" via an unstructured interview) or imitation (e.g., imitating a successful competitor's sales pitch) and can also just result from habit and/or rituals (as has been argued to be the case with many unstructured interviews [Dipboye, 1994]).

When the multiplicity and conflicting nature of institutional pressures make acquiescence impossible, however, organizations may attempt to compromise by balancing, pacifying, or bargaining with external constituents (Oliver, 1991). An example for balancing the need of scientific validity with assessors' desires to rely on clinical judgments would be Kuncel's (2008) recommendation to only present carefully prescreened candidates to decision makers or to use certain data combination methods that permit expert input without seriously impairing the test's validity. Pacifying implies trying to appease or placate the source of the institutional pressure, for example, by acknowledging how "knowledge about assessment centers and related research can provide useful insights and guidance on how IPAs can be further improved" (Silzer \& Jeanneret). At other moments, Silzer and Jeanneret outright bargain about the conditions, few as those may be, when clinical assessors may do as well and possibly better than statistical procedures - not a trivial debate if one considers the social identity attached to this question, together with the need to agree upon scientifically sound standards for professional training and licensure. And although strenuous, such bargaining will serve the discipline considerably better than avoiding the issue by concealing nonconformity (e.g., by designing a structured test and then not using it), escaping from institutional pressures (e.g., by leaving the professional association), or buffering, that is, reducing external inspection, scrutinizing or evaluation (a strategic response that has been associated with the use of poorly documented and unstandardized selection procedures [Dipboye, 19941]. And as such, bargaining is also highly preferable to reactions of defiance, that is, the unequivocal rejection of an institutional pressure by just dismissing, challenging, and attacking it, which would only further the division between proponents of either side within our discipline.

Where we might end up with more furious debates, however, is when it comes to the manipulation of standards, that is, the active attempt to change or exert power over the content or the sources of institutional pressures, be it through cooption, control, or influence. In this regard, I fully agree with Silzer and Jeanneret in their call for more research and faculty involvement in the research on and training of IPA. Thus, although I do not share their perspective on the validity of clinical IPA, I do see such involvement necessary, because-all 
complexities aside-whoever doesn't help row the boat likely also has little say in the direction that it's rowing toward.

\section{References}

Egisdóttir, S., White, M., Spengler, P., Maugherman, A., Anderson, L., Cook, R., Rush, ). (2006). The meta-analysis of clinical judgment project: Fifty-six years of accumulated research on clinical versus statistical prediction. The Counseling Psychologist, 34, 341-382.

Colarelli, S. M., \& Thompson, M. (2008). Stubborn reliance on human nature in employee selection: Statistical decision aids are evolutionarily novel. Industrial and Organizational Psychology, 1. 347-351.

Conway, J. M., \& Peneno, G. M. (1999). Comparing structured interview question types: Construct validity and applicant reactions. journal of Business and Psychology, 13, 485-506.

Day, D. V. (2009). Executive selection is: a process not a decision. Industrial and Organizational Psychology, 2, 159-162.

DiMaggio, P. J., \& Powell, W. W. (1983). The iron cage revisited-Institutional isomorphism and collective rationality in organizational fields. American Sociological Association, 48, 147-160.

Dipboye, R. L. (1992). Selection interviews: Process perspectives. Cincinnati, $\mathrm{OH}$ : South-Western.

Dipboye, R. L. (1994). Structured selection interviews: Why do they work? Why are they underutilized? in N. Anderson \& P. Herriot (Eds.), International handbook of selection and assessment. New York, $N Y$ : Wiley.

Finlav, W., \& Coverdill, ). E. (2002). Headhunters: Matchmaking in the labor market. Ithaca, NY: Cornell University Press.

French, W. L. (1987). The personnel management process. Boston, MA: Houghton Mifflin.

Galaskiewicz, J., \& Wasserman, S. (1989). Mimetic processes within an interorganizational field: An empirical test. Administrative Science Quarterly, 34, 454-479.

Grove, W., Zald, D., Lebow, B., Snitz, B., \& Nelson, C. (2000). Clinical versus mechanical prediction: A meta-analysis. Psýchological Assessment, 12, 19-30.

Harris, L. (2000). Procedural justice and perceptions of fairness in selection practice. International Journal of Selection and Assessment, 8, 148-157.

Highhouse, S. (2008). Stubborn reliance on intuition and subjectivity in employee selection. Industrial and Organizational Psychology, 1, 333-342.

Klehe, U.-C. (2004). Choosing how to choose: Institutional pressure affecting the adoption of personnel selection techniques. Journal of Sefection and Assessment, 12, 315-330.

Klimoski, R., \& jones, R. G. 2008). Intuiting the selection context. Industrial and Organizational Psychology, 1, 352-354.

König, C. I., Klehe, U.-C., Berchtold, M., \& Kleinmann, M. (2010). Reasons for being selective when choosing personnel selection procedures. international journal of Selection and Assessment, $18,17-27$.
Kraut, A. I. (2009). It is not all our fault they don't invite us to the party. Industrial and Organizational Psychology, 2,171-172.

Kuncel, N. R. (2008). Some new (and old) suggestions for improving personnel selection. Industrial and Organizational Psychology, 1, 343-346.

Latham, G. P.. \& Finnegan, B. 1. (1993). Perceived practicality of unstructured, patterned, and situational interviews. In H. Schuler (Ed.), Personnel selection and assessment: Individual and organizational perspectives (pp. 41-55). Hillsdale, NJ: Erlbaum.

Murphy, K. R., \& Davidshofer, C. O. (1991). Psychological testing: Principles and applications (2nd ed.). Upper Saddle River, NI: Prentice-Hall.

Oiver, C. (1991). Strategic responses to institutional processes. Academy of Management Review, 16, $145-179$.

Ones, D. S., \& Dilchert, S. (2009). How special are executives? How special should executive selection be? Observations and recommendations. Industrial and Organizational Psychology, 2, $163-170$.

Pfeffer, l., \& Salancik, G. R. (1978). The external control of organizations. New York, NY: Harper \& Row.

Phillips, J. M., \& Gully, S. M. (2008). The role of perceptions versus reality in managers' choice of selection decision aids. Industrial and Organizational Psychology, 3, 361-363.

Rubenzer, S. I., Faschingbauer, T. R., \& Ones, D. S. (2000). Assessing the U.S. presidents using the revised NEO personality inventory. Assessment, 7, 403-420.

Rynes, S. L., Heneman, H. G., \& Schwab, D. P. (1980). Individual reactions to organizational recruiting: A review. Personnel Psychology, 33, 529-542.

Schneider, B. (1972). Organizational climate: Individual preferences and organizational realities. Journal of Applied Psychology, 56, 211-217.

Schuler, H. (1992). Das multimodale einstellungsinterview [The multimodal employment interview]. Diagnostica, 38, 281-300.

Silzer, R. F. (2005). Playing three-dimensional chess: The complexity of executive success. Presentation at the SIOP Leading Edge Consortium: Leadership at the Top: The Selection, Globalization and Ethics of Executive Talent. St. Louis, Missouri.

Silzer, R., \& leanneret, R. (2011). Individual psychological assessment: A practice and science in search of common ground. Industrial and Organizational Psychology, 4, 270-296.

Smalley, M. D. (2009). The executive job is kaput. Industrial and Organizational Psychology, 2, $173-176$.

Smith, A. B., \& Howard, A. (2009). Executive selection as a strategic business decision. Industrial and Organizational Psychology, 2, 144-150.

Spengler, P., White, M., Egisdóttir, S., Maugherman, A., Anderson, L., Cook, R., et al. (2009). The metaanalysis of clinical judgment project: Effects of experience on judgment accuracy. The Counseling Psychologist, 37, 350-398.

Tolbert, P. S., \& Zucker, L. G. (1983). Institutional sources of change in the formal structure of organizations: The diffusion of civil service reform, 1880-1935. Administrative Science Quarterly, 28, 22-39. 